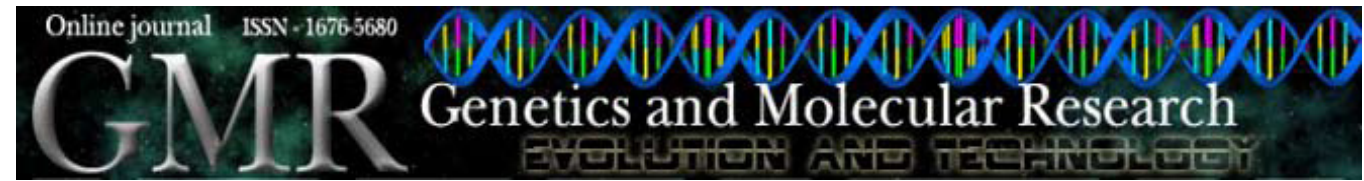

\title{
Rearing Africanized honey bee (Apis mellifera L.) brood under laboratory conditions
}

\author{
I.C. Silva1, D. Message ${ }^{2}$, C.D. Cruz ${ }^{3}$, L.A.O. Campos ${ }^{3}$ and M.J. Sousa-Majer ${ }^{4}$ \\ ${ }^{1}$ Faculdade de Filosofia, Ciências e Letras de Ribeirão Preto, \\ Universidade de São Paulo, Ribeirão Preto, SP, Brasil \\ ${ }^{2}$ Departamento de Biologia Animal, \\ Universidade Federal de Viçosa, Viçosa, MG, Brasil \\ ${ }^{3}$ Departamento de Biologia Geral, \\ Universidade Federal de Viçosa, Viçosa, MG, Brasil \\ ${ }^{4}$ Department of Environmental Biology, \\ Curtin University of Technology, Perth, Australia \\ Corresponding author: I.C. Silva \\ E-mail: icsmel@yahoo.com.br
}

Genet. Mol. Res. 8 (2): 623-629 (2009)

Received December 12, 2008

Accepted January 26, 2009

Published May 26, 2009

\begin{abstract}
We developed a method for rearing larvae of Africanized bees under laboratory conditions to determine the amount of diet needed during larval development to obtain a worker bee. We started with larvae 18-24 h old, which were transferred to polyethylene cell cups and fed for five days. We found that the amount of diet needed for successful larval development was: $4,15,25,50$, and $70 \mu \mathrm{L}$ during the first to fifth days, respectively. The survival rate to the adult stage was $88.6 \%$ when the larvae received the daily amount of diet divided into two feedings, and $80 \%$ when they received only one feeding per day. The adult weight obtained in the laboratory, when the larvae received the daily amount of diet in a single dose, did not differ from those that were developed under field conditions (our control). All adults that we obtained in laboratory appeared to be normal. This technique has the potential to facilitate studies on brood pathogens, resistance mechanisms to diseases and also might be useful to test the impacts of transgenic products on honey bee brood.
\end{abstract}

Key words: Africanized bee; Apis mellifera; Larval rearing; In vitro method 


\section{INTRODUCTION}

Rearing worker bee larvae (Apis mellifera) under laboratory conditions has been done for several purposes, including studies of larval development (Michael and Abramovitz, 1955; Hoffman, 1960; Dixon and Shuel, 1963; Jay, 1964; Shuel and Dixon, 1968; Dietz, 1975; Rembold and Lackner, 1981; Vandenberg and Shimanuki, 1987), caste determination (Dietz and Haydak, 1970; Weiss, 1975; Shuel et al., 1978; Asencot and Lensky, 1976, 1984; Rembold, 1987), caste determination and food consumption (Dietz and Lambremont, 1970), the effects of pathogens (Patel and Gochnauer, 1959; Gilliam et al., 1978; Vandenberg and Shimanuki, 1990; Brodsgaard et al., 1998, 2000), effects of antibiotics and toxicity of insecticides (Wittmann and Engels, 1980; Czoppelt and Rembold, 1988; Peng et al., 1992; Davis et al., 2000), and the impact of transgenic products (Brodsgaard et al., 2003).

Information available on rearing worker larvae under laboratory conditions does not include specifications of the daily amounts of diet supplied to each larva. This kind of information would facilitate research on honey bee brood diseases and for genetic and molecular studies concerning caste determination.

Our objective was to determine the best conditions to rear worker bee larvae of (Africanized) Apis mellifera under laboratory conditions. We started with larvae 18-24 h old and reared them until the adult stage, varying the ratio of the nutrients used in the artificial diet, the quantity of diet and the number of times that the larvae are fed each day, measuring the duration and the viability of the brood in the different stages of the development, and comparing the weight of the adult bees that emerged in the laboratory to bees reared under field conditions.

\section{MATERIAL AND METHODS}

Seven colonies of Africanized honey bees (Apis mellifera) collected from the region of Viçosa, Minas Gerais State, Brazil, and maintained in the Federal University of Viçosa apiary were used to supply larvae. The queen bee was confined to a defined area on a comb containing empty cells for 6 to $8 \mathrm{~h}$ to control the age of the brood. Half of the brood in these marked areas was used for determination of the parameters of larval development under laboratory conditions and the other half was used as a control.

\section{In vitro method}

The artificial diet used for feeding of the larvae was adapted from Rembold and Lackner (1981), with modifications in the ratios of the nutrients, to obtain a diet with $30 \%$ total solids, as recommended by Vandenberg and Shimanuki (1987). The final diet had the following formulation $(\mathrm{w} / \mathrm{w}): 49.0 \%$ royal jelly, $36.3 \%$ water, $6.8 \% \mathrm{~d}$-fructose, $6.8 \% \mathrm{~d}$-glucose, and $1.1 \%$ yeast extract. The sugars and the yeast extract were dissolved in water, filtered through a Millipore membrane $(0.22 \mu \mathrm{m})$, and then added to the royal jelly. Before each experiment, the required amount of diet was prepared and stored at $5^{\circ} \mathrm{C}$ for 5 days.

Ten polyethylene cups $(9.8 \mathrm{~mm}$ height $\mathrm{x} 5.6 \mathrm{~mm}$ in diameter at the base $\mathrm{x} 8.8 \mathrm{~mm}$ in diameter at the top) were attached to a Styrofoam (polystyrene foam) disc and placed into a Petri dish; the cups were individually labeled (Figure 1). The artificial diet was thawed in a water bath at $34^{\circ} \mathrm{C}$ and then transferred to each cup using a micropipette. Larvae from 18 to 
$24 \mathrm{~h}$ old (from the mapped comb) were carefully transferred to these cell cups under aseptic conditions and placed on the artificial diet, using a thin spatula.

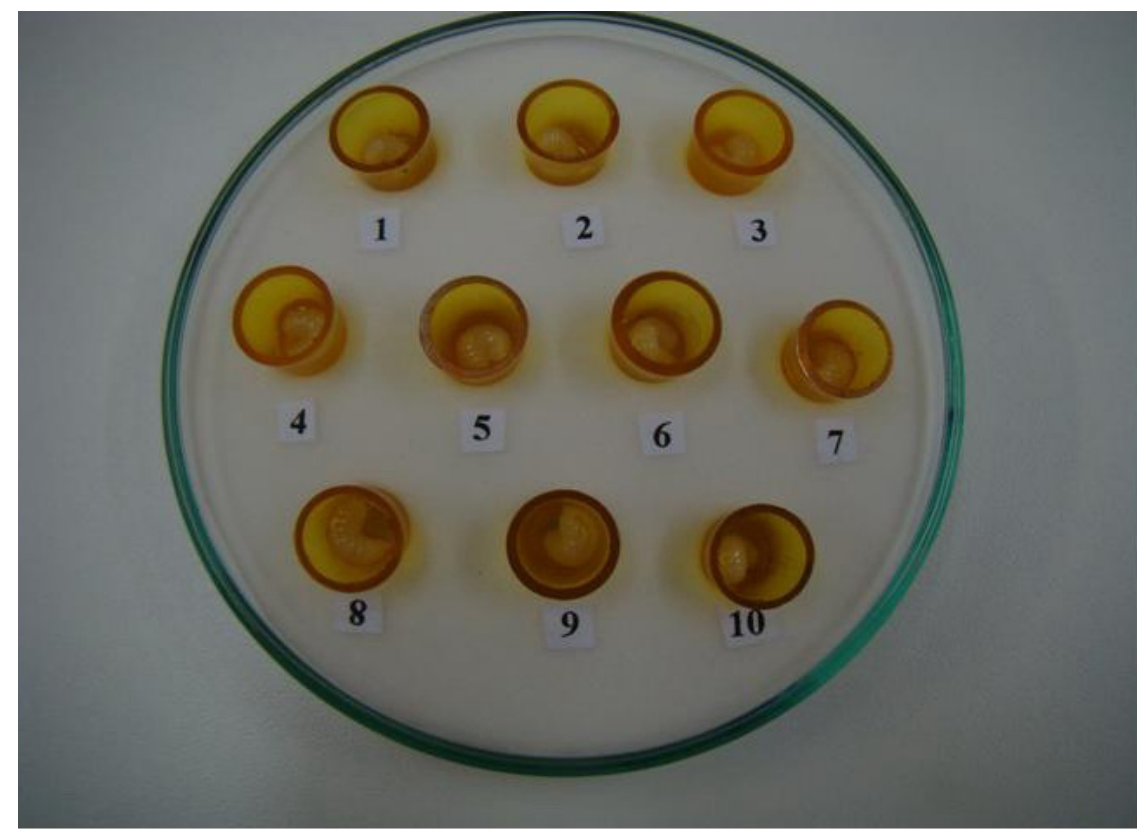

Figure 1. System used for in vitro rearing of honey bee larvae. The cups were identified by different numbers in order to facilitate the recording of the individual larvae.

After the feeding period, larvae were removed from the cups and placed on a double layer of sterile fine cotton gauze inside a clean Petri dish; the space was divided by paper to provide six compartments to maintain the larvae separated. During the feeding and defecation period, the Petri dishes were placed into a desiccator with a controlled $96 \%$ relative humidity, using a $15.5 \%$ glycerol solution; the desiccator was maintained in an incubator at $34^{\circ} \mathrm{C}$.

After the larvae defecated, they were transferred to new Petri dishes, until adult emergence. During this period, these Petri dishes were kept inside an incubator $\left(34^{\circ} \mathrm{C}\right)$ with the relative humidity controlled at $70 \%$, using a $23 \% \mathrm{KOH}$ solution inside the desiccator.

\section{Determination of daily amount of artificial diet to be fed to each larva}

We ran a preliminary test to determine the daily amount of artificial diet to be offered to each larva. Based on Parra (1991), the daily amount of artificial diet given for each larva was calculated by determining the difference between the amount of the food given each day during the feeding period and what was left over in the cells after $24 \mathrm{~h}$. Larvae 18 to $24 \mathrm{~h}$ old were transferred to polyethylene cups or wax cups containing arti- 
ficial diet in excess. After $24 \mathrm{~h}$, the larvae were individually removed and transferred to another cup containing the amount of food allocated for the second day, and so successively, until the fifth day. The daily diet consumed by each age of larva during the feeding period was determined using an analytical balance with a precision of $0.1 \mathrm{mg}$. This was calculated based on the average consumption of artificial diet used by 65 larvae that reached the adult phase with a weight similar to that of adult workers that had been reared naturally in the same colonies from which the laboratory-reared larvae originated.

\section{Brood development time and viability when reared under field and laboratory conditions}

An experiment was set up to determine whether the viability of the larvae differed if they were fed only once or twice per day. Twenty larvae (18 to $24 \mathrm{~h}$ old) from each of the same seven colonies were collected and transferred to two Petri dishes, each one containing 10 larvae. Half the larvae received the daily amount of diet in a single feeding and the other half received the diet divided into two feedings. The development time for the larval and pupal phases under field and laboratory conditions, and the survival rate (from the original larval transfer until the pre-defecation larval period [S1], from then until the white-eye pupal phase [S2], and from then until adult emergence [S3]) were compared using the Student $t$-test $(\alpha=0.05)$.

\section{Caste determination and weight of newly emerged adult bees under field and laboratory conditions}

To determine whether adult bees developed under laboratory conditions were similar to those reared under field conditions, 10 newly emerged adult workers from each of the seven colonies were collected and compared to groups of 10 newly emerged adult workers (from the same colonies) that developed under laboratory conditions. The adult bees were weighed using an analytical balance with a precision of $0.1 \mathrm{mg}$; after that the newly emerged adult bees were conserved by immersing them in a Bouin alcohol solution for $24 \mathrm{~h}$ and then in $70 \%$ ethanol to be examined for caste characters. To distinguish whether the adult newly emerged bees under field and laboratory conditions were workers, inter-castes or queen, the following morphological characteristics were observed: mandible and sting morphology, presence or absence of pollen basket on the hind tibia, and the hair distribution pattern on the inward face of the basitarsus (third leg pairs). The mean weights were compared by the Tukey test, at a significance level of $\mathrm{P}=0.05$.

\section{RESULTS AND DISCUSSION}

The optimum amounts of diet to be provided to larvae from 18 to $24 \mathrm{~h}$ old on the $1 \mathrm{st}$, 2nd, 3rd, 4th, and 5th days were $4,15,25,50$, and $70 \mu \mathrm{L}$, respectively.

The survival rates (\%) of Africanized bees (Table 1) from the transference day (first day) to the pre-defecation larval period, to the white-eye pupae and to the adult emergence day under laboratory conditions were 93,90 , and 89 for brood receiving the diet daily divided into two feedings, and 90,84 , and 80 , respectively, when they received only one feeding. 


\begin{tabular}{|c|c|c|c|c|c|c|}
\hline \multirow[t]{2}{*}{ Colony } & \multicolumn{2}{|c|}{$\mathrm{S} 1$} & \multicolumn{2}{|c|}{$\mathrm{S} 2$} & \multicolumn{2}{|c|}{ S 3} \\
\hline & DF & SF & $\mathrm{DF}$ & SF & DF & SF \\
\hline 1 & 8 & 10 & 8 & 9 & 8 & 8 \\
\hline 2 & 10 & 9 & 10 & 9 & 9 & 8 \\
\hline 3 & 10 & 10 & 10 & 10 & 10 & 9 \\
\hline 4 & 9 & 9 & 8 & 8 & 8 & 8 \\
\hline 5 & 9 & 10 & 8 & 9 & 8 & 9 \\
\hline 6 & 10 & 8 & 10 & 7 & 10 & 7 \\
\hline 7 & 9 & 7 & 9 & 7 & 9 & 7 \\
\hline Mean (\%) & 93 & 90 & 90 & 84 & 89 & 80 \\
\hline
\end{tabular}

$\mathrm{S} 1=$ brood survival from 18-24 $\mathrm{h}$ larvae to pre-defecating larvae; $\mathrm{S} 2$ = brood survival from $18-24 \mathrm{~h}$ larvae to whiteeyed pupa; $\mathrm{S} 3$ = brood survival from 18-24 h larvae to emerging adult bees.

There were no significant differences in the survival rates for larvae receiving only one versus two feedings/day. Rembold and Lackner (1981) achieved a 75\% survival until adult emergence, but did not mention the larval and pupal survival rates. Vandenberg and Shimanuki (1987) reported $92 \%$ larval survival and $75 \%$ survival until adult emergence, using wax cups. They reported only $57 \%$ of larval survival with polyethylene cups. Peng et al. (1992) reported that they obtained $90.5 \%$ larval survival but only $74.5 \%$ survival until adult emergence. Brodsgaard et al. (2000) reported $75 \%$ survival until the adults emerged. Unfortunately, in all of these reports, the amounts of food provided to the brood were not mentioned. We found a mean survival rate of $89 \%$ for two daily feedings, and $80 \%$ for only one feeding. Given that the survival rate that we obtained was superior to that of the published reported we have cited, we conclude that the amounts of diets that we used $(4,15,25,50$, and $70 \mu \mathrm{L})$ were sufficient for normal development.

The brood development time from the just-born larva to white-eye pupa and from white-eye pupa to just-emerge adult bee were, respectively, nine and eight days. Then, the developing time from the time the eggs were laid to the time the adult bees emerge was 20 days, both for those bees developed under the laboratory as for those developed in field conditions (control). These results agree with Garófalo (1977) and Michelette and Soares (1993) who reported similar results when they had observed the development of Africanized bees under natural conditions.

In this study, the honeybees developed under laboratory conditions presented pollen basket, sting, distribution of the hairs in the inward face of basitarsus and mandibles similar to the worker bees that were developed under field conditions, also showing that the amount and the quality of the artificial diet provided to the larvae had been adequate, not affecting the caste determination.

The comparison between the mean adult worker weight of the bees, reared under laboratory and field conditions, is shown at Table 2 . The weight of the adult bees that were reared under laboratory conditions did not differ when the two feeding systems were tested. Except, in the colonies No. 2 and No. 7, the weight of the adult bees differed statistically from the control ones, when they received their daily artificial diet using two feedings. However, this difference was not observed for the adult bees receiving their daily artificial diet in a single feeding. 


\begin{tabular}{|c|c|c|c|}
\hline \multirow{2}{*}{ Colonies } & \multicolumn{2}{|c|}{ Laboratory } & \multirow[t]{2}{*}{ Control (field) } \\
\hline & $\mathrm{DF}$ & $\mathrm{SF}$ & \\
\hline 1 & $91.6^{\mathrm{a}}(8)$ & $90.9^{\mathrm{a}}(8)$ & $96.1^{\mathrm{a}}(10)$ \\
\hline 2 & $86.1^{b}(9)$ & $95.6^{\mathrm{ab}}(8)$ & $97.9^{\mathrm{a}}(10)$ \\
\hline 3 & $100.7^{\mathrm{a}}(10)$ & $98.9^{\mathrm{a}}(9)$ & $96.5^{\mathrm{a}}(10)$ \\
\hline 4 & $93.7^{\mathrm{a}}(8)$ & $100.8^{\mathrm{a}}(8)$ & $95.5^{\mathrm{a}}(10)$ \\
\hline 5 & $98.3^{\mathrm{a}}(8)$ & $89.9^{\mathrm{a}}(9)$ & $98.2^{\mathrm{a}}(10)$ \\
\hline 6 & $88.9^{\mathrm{a}}(10)$ & $91.7^{\mathrm{a}}(7)$ & $94.9^{\mathrm{a}}(10)$ \\
\hline 7 & $84.5^{\mathrm{b}}(9)$ & $89.7^{\mathrm{ab}}(7)$ & $97.4^{\mathrm{a}}(10)$ \\
\hline
\end{tabular}

Number of bees for each mean in parentheses. Means followed by the same superscript letters in the same line are not significantly different by the Tukey test $(5 \%)$. DF $=$ larvae fed the diet divided into two feedings; $\mathrm{SF}=$ larvae fed the daily amount of diet in a single feeding.

This brood rearing technique using artificial diet will be useful for studies under laboratory conditions without the interference of nurse bees.

\section{ACKNOWLEDGMENTS}

\section{Research supported by CAPES, FAPEMIG and CNPq.}

\section{REFERENCES}

Asencot M and Lensky Y (1976). The effect of sugars and juvenile hormone on the differentiation of the female honeybee larvae (Apis mellifera L.) to queens. Life Sci. 18: 693-699.

Asencot M and Lensky Y (1984). Juvenile hormone induction of queenliness on female honey bee (Apis mellifera L.) larvae reared on worker jelly and on stored royal jelly. Comp. Biochem. Physiol. B Biochem. Mol. Biol. 78B: 109-117.

Brodsgaard C, Ritter W and Hansen H (1998). Response of in vitro reared honeybee larvae to various doses of Paenibacillus larvae larvae spores. Apidologie 29: 569-578.

Brodsgaard C, Hansen H and Ritter W (2000). Progress of Paenibacillus larvae larvae infection in individually inoculated honeybee larvae reared singly in vitro, in micro colonies, or in full-size colonies. J. Apic. Res. 39: 19-27.

Brodsgaard HF, Brodsgaard CJ, Hansen H and Lövei GL (2003). Environmental risk assessment of transgene products using honey bee (Apis mellifera) larvae. Apidologie 34: 139-145.

Czoppelt C and Rembold H (1988). Effect of parathion on honey bee larvae reared in vitro. J. Pest Sci. 61: 95-100.

Davis AR, Solomon KR and Shuel RW (2000). Laboratory studies of honeybee larval growth and development as affected by systemic insecticides at adult-sublethal levels. J. Apic. Res. 27: 146-161.

Dietz A (1975). Effect of three relative humidities and homogenizing royal jelly on body weight and survival of honey bee larvae in the laboratory. J. Ga. Entomol. Soc. 10: 259-261.

Dietz A and Haydak MH (1970). The effect of royal jelly refrigerated for several years on growth and development of larval female honey bees. J. Ga. Entomol. Soc. 5: 203-206.

Dietz A and Lambremont EN (1970). Caste determination in honey bees. II. Food consumption of individual honeybee larvae determined with P-labeled royal jelly. Ann. Entomol. Soc. Am. 63: 1342-1345.

Dixon SE and Shuel RW (1963). Studies in the mode of action of royal jelly in honeybee development. III. The effect of experimental variation in diet on growth and metabolism of honeybee larvae. Can. J. Zool. 41: 733-739.

Garófalo CA (1977). Brood viability in normal colonies of Apis mellifera. J. Apic. Res. 1: 3-13.

Gilliam M, Taber S III and Rose JB (1978). Chalkbrood disease of honey bees, Apis mellifera L.: a progress report. Apidologie 9: 75-89.

Hoffman I (1960). Rearing worker honeybee larvae in an incubator. Bee World 41: 10-11.

Jay SC (1964). Rearing honeybee brood outside the hive. J. Apic. Res. 3: 51-60. 
Michael AS and Abramovitz M (1955). A method of rearing honey bee larvae in vitro. J. Econ. Entomol. 48: 43-44.

Michelette ERF and Soares AEE (1993). Characterization of preimaginal developmental stages in Africanized honey bee workers (Apis mellifera L). Apidologie 24: 431-440.

Parra JRP (1991). Consumo e Utilização de Alimentos por Insetos. In: Ecologia Nutricional de Insetos e suas Implicações no Manejo de Pragas (Panizzi AR and Parra JRP, eds.). CNPq/Manole, São Paulo, 9-65.

Patel NG and Gochnauer TA (1959). The toxicity of extracts from foulbrood scale residues for honey-bee larvae maintained in vitro. J. Insect Pathol. 1: 190-192.

Peng YSC, Mussen E, Fong A, Montague MA, et al. (1992). Effects of chlortetracycline of honey bee worker larvae reared in vitro. J. Invert. Pathol. 60: 127-133.

Rembold H (1987). Caste-specific modulation of juvenile hormone titers in Apis mellifera. Insect Biochem. 17: 1003-1006.

Rembold H and Lackner B (1981). Rearing of honeybee larvae in vitro: effect of yeast extract on queen differentiation. $J$. Apic. Res. 20: 165-171.

Shuel RW and Dixon SE (1968). The importance of sugar for the pupation of the worker honeybee. J. Apic. Res. 7: 109-112.

Shuel RW, Dixon SE and Kinoshita GB (1978). Growth and development of honeybees in the laboratory on altered queen and worker diets. J. Apic. Res. 17: 57-68.

Vandenberg JD and Shimanuki H (1987). Technique for rearing worker honey bees in the laboratory. J. Apic. Res. 26: 90-97.

Vandenberg JD and Shimanuki H (1990). Isolation and characterization of Bacillus coagulans associated with half-moon disorder of honey bees. Apidologie 21: 233-241.

Weiss K (1975). Zur kastenspezifischen ernahrung der weiblichen bienenlarve (Apis mellifica L.) (To the caste specific nutrition of femal honey bee larvae (Apis mellifica L.). Apidologie 6: 95-120.

Wittmann D and Engels W (1980). Development of Test Systems for Insecticide Effects of Honey Bee Larvae. In: Symposium of the Harmonisation of the Methods for Testing the Toxicity of Pesticides to Bees, September 23-25, 1980, Wageningen, 1-10. 